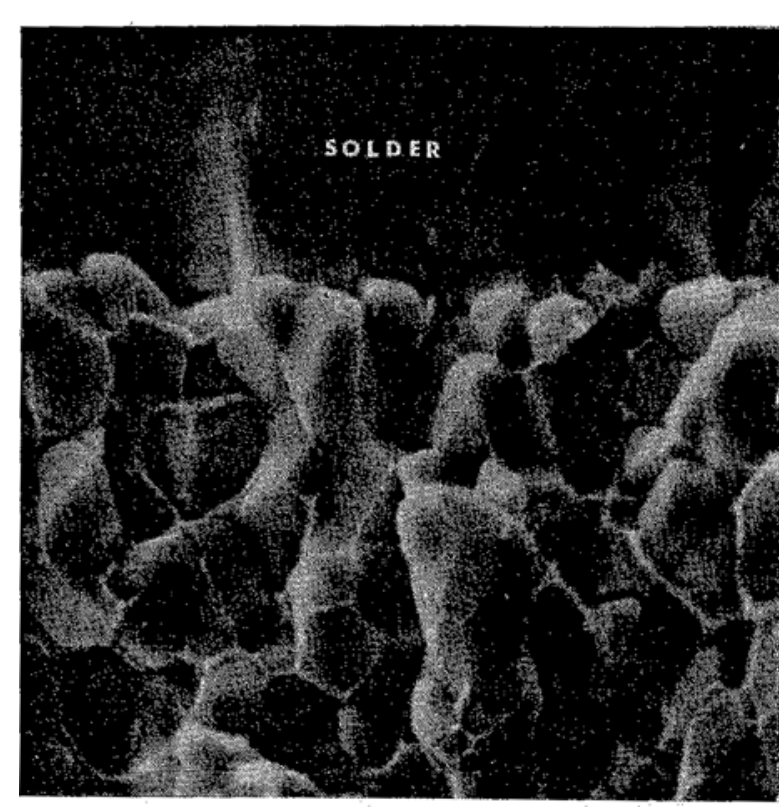

Fig. 12 The solder reaction layer interface showing the nodular form of the intermetallic, AuIn ${ }_{2}$, which is embedded in lead and results in a ductile layer

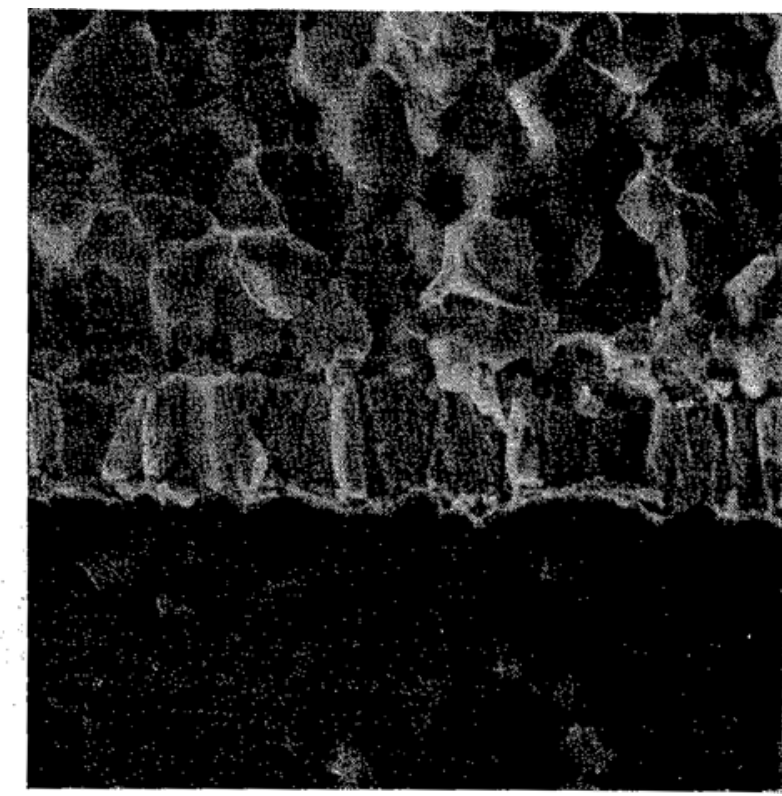

Fig. 13 A second reaction layer consists of columns of $\mathrm{Au}_{9} \mathrm{In}_{4}$. This could impair the mechanical integrity of the solder joint

$$
\times \mathbf{4 0 0 0}
$$

solders was demonstrated. Soldering parameters such as substrate temperature, flux type and solder size can be investigated rapidly and with minimum effort. Ageing of lead-indium solder joints on gold films was discussed in light of the intermetallic reaction layer which grows rapidly. This reaction layer consists of a lead rich $\propto$ phase which surrounds nodules of $\mathrm{AuIn}_{2}$. This layer was proven to be relatively soft. Conditions necessary for the growth of a single phase layer of $\mathrm{Au}_{9} \mathrm{In}_{4}$ were stated as thin solder or thick gold, both of which lead to indium depletion which causes compound formation.

Thus, from a fuller understanding of the various factors involved, it can be seen that lead-indium solders cause appreciably less scavenging damage than do lead-tin solders and are therefore satisfactory for use on gold films thicker than $1 \mu \mathrm{m}$. In addition, providing the thicknesses of the gold and the leadindium solder layers are in the correct proportion and the gold layer does not exceed $10 \mu \mathrm{m}$, the forma- tion of brittle intermetallic layers can be avoided and satisfactory joints produced.

\section{Acknowledgements}

This work was supported by the U.S. Energy Research and Development Administration.

\section{References}

1 J. D. Braun, Trans. A.S.M., 1964, 57, (1), 568

2 J. D. Braun, ibid, 1965, 58, (1), 434

3 C. R. Jackson, Circuits Manufacturing, 1973, 40

4 F. G. Yost, F. P. Ganyard and M. M. Karnowsky, Met. Trans. A, 1976, 7, (8), 1141

5 M. M. Karnowsky and F. G. Yost, Met. Trans. A, 1976, 7, (8), 1149

6 F. G. Yost, Proceedings of the 1976 International Microelectronics Symposium, 1976, 61

7 T. Heumann and B. Predel, Z. Metallkunde, 1966, 57, (1), 50

8 E. Nembach, Trans. A.I.M.E., 1969, 245, 131

9 Y. Koike and J. M. Sivertsen, F. Phys. Soc. Fapan, 1970, 29, (5), 1235

10 M. M. Karnowsky and A. Rosenzweig, Trans. A.I.M.E., $1968,242,2257$

11 J. B. Long, F. Electrochem. Soc., 1975, 122, (2), 25C

\title{
Radioactive Gold for Investigating the Efficiency of Mixing of Granular Solids
}

The neutron-heavy radioisotope of gold, ${ }_{79}^{198} \mathrm{Au}$, has a half life of 2.7 days and has found application in a number of tracer studies. It has been used for example in investigations on the continuous casting of steel and in following the movement of sea sediments. It has now been reported by $A$. Rafalski and his colleagues at the Institute for Nuclear Research in Warsaw as an effective tool for investigation of the efficiency of mixing equipment for the blending of granular solids (A.
Rafalski, J. Palige, Z. Bazaniak and J. St. Michalik, Isotopenpraxis, 1977, 13, (2), 62-67).

These authors applied the ${ }_{79}^{198} \mathrm{Au}$ in the form of solutions of $\mathrm{HAuCl}_{4}$ in hydrochloric acid for the labelling of materials being fed to the mixing installation used for the preparation of the sinter mixtures in a zinc production plant. After application the gold was not susceptibie to elution and the method is claimed as being generally applicable to problems of this type. 